\section{Frequency and Timing of Leaf Removal Affect Growth and Podophyllotoxin Content of American Mayapple in Shade}

\author{
Kent E. Cushman ${ }^{1}$ \\ Southwest Florida Research and Education Center, University of Florida, Institute \\ of Food and Agricultural Sciences, Immokalee, FL 34142
}

Rita M. Moraes

National Centerfor Natural Products Research, Thad Cochran Research Center, School of Pharmacy, University of Mississippi, University, MS 38677

Patrick D. Gerard

Experimental Statistics Unit, Mississippi State University, Box 9653, Mississippi

State, MS 39762

\author{
Ebru Bedir, Bladimiro Silva, and Ikhlas A. Khan \\ National Center for Natural Products Research, Thad Cochran Research Center, \\ School of Pharmacy, University of Mississippi, University, MS 38677
}

Additional index words. Podophyllum peltatum, lignan, $\alpha$-peltatin, $\beta$-peltatin, defoliation.

\begin{abstract}
Leaves of American mayapple (Podophyllum peltatum) are being investigated as an alternative and renewable source of podophyllotoxin, a pharmaceutical compound used in the manufacture of several drugs. This study examined long-term performance of mayapple populations subjected to different harvest strategies. A naturally occurring population in shade was subjected to leaf removal treatments of frequency (every year, every 2 nd or 3rd year) or timing (early or late season). Plots were $1.0 \mathrm{~m}^{2}$, established during Spring 2001, and treatments were applied from 2001 to 2004 . Control plots not previously harvested were also included each year. Plants did not tolerate the severest of leaf removal treatments: early harvest time in combination with annual harvest frequency. Early annual harvests reduced total leaf dry mass and total leaf area in a quadratic manner. Late harvest conducted annually, and early harvest conducted every other year, also reduced leaf dry mass and area but not as much as early annual harvest. Plants harvested every year, early, or early every year produced fewer sexual shoots than other treatment combinations. Contents of $\alpha$-peltatin, $\beta$-peltatin, and total lignans were higher for leaves harvested early than those harvested late during each year of the study, demonstrating that lignan contents were affected by leaf age and not treatment. In conclusion, our results for plants grown in shade show that leaves can be removed late in the growing season every 2nd or 3rd year or early every 3rd year without reducing long-term performance of the population. This is more restrictive than that reported for populations in full sun where plants tolerated late harvests every year.
\end{abstract}

Leaves and rhizomes of American mayapple, Podophyllum peltatum L., contain the pharmaceutical compound podophyllotoxin. The compound is used in the manufacture of drugs for the treatment of cancer, arthritis, and various skin conditions such as psoriasis and genital warts (Bedows and Hatfield, 1982; Jackson and Dewick, 1985; Lerndal and Svensson, 2000) Currently, podophyllotoxin is extracted from rhizomes of the Indian mayapple (P. emodi Wall.; syn. $P$. hexandrum Royle), but excessive and destructive harvests were reported to threaten the plant in its native habitat of the Himalayas (Foster, 1993; Rai et al., 2000). American may-

Received for publication 12 Jan. 2005. Accepted for publication $26 \mathrm{Feb}$. 2006. This research was supported by NRI Competitive Grant Program 71.2, Award \#2002-01525, and Specific Cooperative Agreement No. 58-6408-7-012.

${ }^{1}$ To whom reprint requests should be addressed; e-mailkcushman@ufl.edu.

apple is being investigated as an alternative and potential domestic source of podophyllotoxin. It is a low-growing and herbaceous species that emerges from underground rhizomes relatively early in the spring to capture mottled sunlight under trees notyet in full foliage. The plant forms colonies and, at times, can be found thriving in full sun. It grows throughout eastern North America from Quebec and Minnesota in the north to Florida and Texas in the south (Meijer, 1974; Pearce and Thieret, 1993).

Podophyllotoxin content in leaves of American mayapple varies greatly, and accessions collected from wild populations were reported to range from zero to $56 \mathrm{mg} \cdot \mathrm{g}^{-1}$ (Moraes et al., 2002, 2005). If domesticated, it is expected that commercial plantings would use only accessions with the highest levels of the compound, thus providing the highest return to growers of specialty crops serving the pharmaceutical industry (Meijer, 1974; Moraes et al., 2000). Recent research showed the species to be relatively easy to manipulate using common horticultural practices (Cushman et al., 2005a, 2005b; Cushman and Maqbool, 2005). In addition, increasing levels of shade were reported to result in decreasing podophyllotoxin content (Cushman et al., 2005b; Moraes et al., 2005). Other lignans found in mayapple leaves, of secondary interest as pharmaceutical compounds, are $\alpha$-peltatin, $\beta$-peltatin, and epipodophyllotoxin.

It is envisioned that commercial production would involve harvest of leaves and not rhizomes, leaving rhizomes intact to produce shoots and leafbiomass for annual harvest. Relatively slow-growing species such as mayapple, however, do not appear to tolerate leaf removal. Increasing defoliation of Trillium grandiflorum (Michaux) Salisbury, a spring ephemeral similar to mayapple, resulted in decreasing rhizome density and total non-structural carbohydrates (Lubbers and Lechowicz, 1989). Partial defoliation of two out of four spring ephemeral species, Jeffersonia diphylla L. and Trillium sessile L., resulted in decreased reproductive performance during the second year of the study (Rockwood and Lobstein, 1994). Long-term performance of the species used in these studies was not reported, and botanical investigations of defoliation tend to focus on herbivory and reproductive fitness rather than horticultural aspects such as yield. The overall goal of the research reported here was to explore sustainable harvest procedures for use in perennial mayapple plantings. Frequency and timing of leaf removal was investigated to test the longterm effects of harvest strategy on leaf biomass yield and podophyllotoxin content. It was not known at the beginning of this study whether commercial plantings would be established in shade or full sun, and the research presented here was conducted with a wild population in shade. Awell-established population in the wild was used to avoid years of preparation to plant and establish a stable population from which to begin the study. Similar research using a wild population in full sun was reported by Cushman et al. (2006).

\section{Materials and Methods}

This study was conducted using a naturallyoccurring population of American mayapple located in Natchez, Miss. (longitude $-91.400^{\circ}$, latitude $31.435^{\circ}$, elevation $72 \mathrm{~m}$ ). A herbarium voucher specimen was deposited at the Pullen Herbarium, The University of Mississippi, accession number 65130 . The mayapple population was well established, had established naturally, and was located in a shady site populated by a mixture of 30- to 50-year-old hardwood tree species (Quercus nigra, Q. velutina, Ostyra virginiana, Acer negundo, Cornus florida, Asimina triloba, Celtis laevigata and Prunus serotina). Early in the last century the site was repeatedly farmed in cotton and then at some time abandoned. Mayapple shoots emerged in early spring about the second week of March and began to senesce from the last week of April to the first week of May.

Research plots were established during Spring 2001. Each plot was marked with four 
wooden stakes placed at the corners of an area $1.0 \times 1.0 \mathrm{~m}$ square. Plots were selected to include plants of average or slightly above average growth and density compared to the surrounding population. Plots were located away from any unusual growths or abnormalities. Leaves of sexual shoots (normally two leaves per shoot) were harvested separately from those of asexual shoots (normally one leafper shoot). Treatments were a factorial arrangement of frequency of harvest (every year, every 2nd or 3rd year) and time of harvest (early or late). Early harvest was defined as the earliest time after shoot emergence when leaves were fully expanded. Late harvest was defined as the time leaves began to senesce by exhibiting yellowing but before they began to turn brown. Controls were plots that had not been previously harvested at any other time during the study. The experimental design was a randomized complete block with four replications. Data were not available each year for all treatments due to the nature of the study (harvest every year or every 2 nd or 3 rd year) and therefore statistical analyses were performed by year.

Leaves were collected for early harvest on 27 Mar. 2001, 25 Mar. 2002, 27 Mar. 2003, and
31 Mar. 2004. Leaves were collected for late harvest on 4 May 2001, 23 Apr. 2002, 17 Apr. 2003, and 29 Apr. 2004. Leaves were harvested within each $1.0 \mathrm{~m}^{2}$ plot according to shoot type and counted. Leaf area was recorded using an area meter (LI-3100; LI-COR, Lincoln, Neb.). Before each harvest leaves were removed from a $0.5-\mathrm{m}$-wide band around the outside perimeter of each plot. These leaves were discarded, but this procedure assured that rhizomes growing into the treatment area throughout the duration of the study would produce shoots that had been treated the same as shoots arising from rhizomes within each plot.

Leaves were dried in a forced-air, constanttemperature oven (1380FM, VWR Scientific Products, Cornelius, Ore.) at $40^{\circ} \mathrm{C}$ and dry mass recorded. This temperature was lower than that used for drying most other plant samples but was the recommended temperature for samples from which lignans are extracted. Samples were then analyzed for lignan content by the National Center for Natural Products Research at the University of Mississippi. Podophyllotoxin, $\alpha$-peltatin, and $\beta$-peltatin were extracted and quantified according to Canel et al. (2000). Data were analyzed using the Mixed procedure of
SAS (SAS Institute Inc., Cary, N.C.) and means separation was by LSD at $P \leq 0.05$. Regression analysis was used to evaluate and compare possible linear and quadratic trends over time for plots harvested early and late each year. Control plots each year were also subjected to regression analysis to evaluate trends for early and late harvests. The Mixed Procedure was used with a first order autoregressive correlation adjustment for repeated measures on plots over time.

\section{Results}

Harvest frequency and harvest time affected mayapple growth during 2002, just one year after treatments were first applied. Total leafarea and leaf dry mass were less for plants harvested 2 years in a row compared to those not previously harvested and less for plants harvested early compared to those harvested late (Table 1). During 2003 and 2004, harvest frequency interacted with harvest time to greatly affect mayapple growth. Two treatment combinations accounted for the interaction during 2003: 1) early harvest every year and 2) early harvest every other year. Two treatment combinations

Table 1. Leaf area, leaf dry mass, shoot number, and ratio of sexual to total number of shoots of American mayapple. Leaf removal frequency (every year or every 2nd or 3rd year) and timing (early or late season) was investigated using a well-established wild population in shade from 2001 to 2004.

\begin{tabular}{|c|c|c|c|c|c|c|c|c|c|c|c|c|c|c|c|c|c|}
\hline \multirow{2}{*}{$\begin{array}{l}\text { Frequency } \\
\text { of harvest }\end{array}$} & \multirow{2}{*}{$\begin{array}{l}\text { Time of } \\
\text { harvest }\end{array}$} & \multicolumn{4}{|c|}{$\begin{array}{c}\text { Leaf area } \\
\left(\mathrm{m}^{2} \cdot \mathrm{m}^{-2}\right)\end{array}$} & \multicolumn{4}{|c|}{$\begin{array}{l}\text { Leaf dry mass } \\
\quad\left(\mathrm{g} \cdot \mathrm{m}^{-2}\right)\end{array}$} & \multicolumn{4}{|c|}{$\begin{array}{l}\text { Shoot no. } \\
\left(\text { shoots } / \mathrm{m}^{2}\right)\end{array}$} & \multicolumn{4}{|c|}{$\begin{array}{l}\text { Ratio of sexual to total shoots } \\
\text { (sexual/total) }\end{array}$} \\
\hline & & 2001 & $2002^{z}$ & 2003 & 2004 & 2001 & 2002 & 2003 & 2004 & 2001 & 2002 & 2003 & 2004 & 2001 & 2002 & 2003 & 2004 \\
\hline Every year & & 0.73 & $0.64 \mathrm{~b}$ & 0.59 & 0.35 & 19 & $14 \mathrm{~b}$ & 14 & 10 & 58 & 53 & 61 & 49 & 0.14 & 0.04 & $0.01 \mathrm{~b}$ & $0.01 \mathrm{c}$ \\
\hline Every 2 years & & 0.83 & --- & 0.76 & --- & 23 & --- & 19 & --- & 52 & -- & 57 & --- & 0.12 & --- & $0.04 \mathrm{a}$ & -- \\
\hline Every 3 years & & 0.90 & --- & -- & 0.88 & 24 & --- & --- & 24 & 57 & --- & --- & 54 & 0.08 & --- & --- & $0.07 \mathrm{~b}$ \\
\hline Control 1 & & --- & $0.88 \mathrm{a}$ & -- & --- & --- & $18 \mathrm{a}$ & --- & --- & --- & 61 & --- & --- & --- & 0.11 & --- & -- \\
\hline Control 2 & & --- & --- & 1.08 & --- & --- & --- & 27 & --- & --- & -- & 66 & --- & --- & --- & $0.07 \mathrm{a}$ & --- \\
\hline \multirow[t]{3}{*}{ Control 3} & & --- & --- & --- & 0.91 & --- & --- & --- & 25 & --- & --- & --- & 58 & --- & -- & --- & $0.14 \mathrm{a}$ \\
\hline & Early & 0.88 & $0.57 \mathrm{~b}$ & 0.63 & 0.75 & 23 & $13 \mathrm{~b}$ & 16 & 20 & 60 & 61 & 59 & 53 & 0.07 & 0.07 & $0.02 \mathrm{~b}$ & 0.07 \\
\hline & Late & 0.76 & $0.94 \mathrm{a}$ & 0.99 & 0.68 & 21 & $19 \mathrm{a}$ & 24 & 19 & 51 & 53 & 63 & 54 & 0.15 & 0.08 & $0.06 \mathrm{a}$ & 0.07 \\
\hline \multirow[t]{2}{*}{ Every year } & Early & 0.78 & 0.41 & $0.22 \mathrm{c}$ & $0.16 \mathrm{c}$ & 20 & 9 & $6 \mathrm{c}$ & $4 \mathrm{c}$ & 64 & 58 & 52 & 43 & 0.04 & $0.00 \mathrm{~b}$ & 0.00 & 0.00 \\
\hline & Late & 0.67 & 0.87 & $0.96 \mathrm{a}$ & $0.53 \mathrm{~b}$ & 18 & 18 & $23 \mathrm{a}$ & $18 \mathrm{~b}$ & 54 & 49 & 71 & 54 & 0.24 & $0.08 \mathrm{a}$ & 0.02 & 0.02 \\
\hline \multirow[t]{2}{*}{ Every 2 years } & Early & 0.89 & -- & $0.64 \mathrm{~b}$ & -- & 25 & --- & $17 \mathrm{~b}$ & -- & 56 & --- & 61 & --- & 0.10 & -- & 0.00 & -- \\
\hline & Late & 0.78 & --- & $0.89 \mathrm{a}$ & -- & 21 & --- & $23 \mathrm{a}$ & -- & 47 & --- & 53 & --- & 0.13 & --- & 0.08 & -- \\
\hline \multirow[t]{2}{*}{ Every 3 years } & Early & 0.98 & --- & --- & $1.04 \mathrm{a}$ & 25 & --- & --- & $27 \mathrm{a}$ & 60 & --- & --- & 57 & 0.08 & -- & --- & 0.06 \\
\hline & Late & 0.82 & -- & -- & $0.73 \mathrm{a}$ & 22 & -- & --- & $22 \mathrm{ab}$ & 54 & -- & --- & 51 & 0.08 & -- & --- & 0.08 \\
\hline \multirow[t]{2}{*}{ Control 1} & Early & --- & 0.74 & -- & --- & --- & 17 & --- & --- & --- & 65 & --- & --- & --- & $0.14 \mathrm{a}$ & --- & --- \\
\hline & Late & --- & 1.01 & --- & --- & --- & 20 & --- & --- & --- & 58 & -- & --- & --- & $0.08 \mathrm{a}$ & --- & --- \\
\hline \multirow[t]{2}{*}{ Control 2} & Early & --- & --- & $1.04 \mathrm{a}$ & --- & --- & --- & $27 \mathrm{a}$ & --- & --- & -- & 66 & --- & --- & --- & 0.05 & -- \\
\hline & Late & --- & --- & $1.12 \mathrm{a}$ & --- & --- & --- & $28 \mathrm{a}$ & --- & --- & --- & 66 & --- & --- & --- & 0.08 & -- \\
\hline \multirow[t]{2}{*}{ Control 3} & Early & --- & --- & --- & $1.05 \mathrm{a}$ & --- & --- & --- & $28 \mathrm{a}$ & --- & --- & --- & 60 & --- & --- & --- & 0.15 \\
\hline & Late & --- & --- & -- & $0.76 \mathrm{a}$ & --- & -- & --- & $22 \mathrm{ab}$ & --- & --- & -- & 57 & --- & -- & --- & 0.12 \\
\hline \multicolumn{18}{|l|}{ Significance } \\
\hline Frequency & & 0.1246 & 0.0117 & 0.0001 & $<.0001$ & 0.1051 & 0.0244 & $<.0001$ & $<.0001$ & 0.3105 & 0.1487 & 0.6322 & 0.5633 & 0.5710 & 0.0436 & 0.0279 & 0.0213 \\
\hline Time & & 0.0842 & 0.0007 & 0.0002 & 0.3940 & 0.1870 & 0.0052 & $<.0001$ & 0.8404 & 0.0524 & 0.1543 & 0.6362 & 0.9375 & 0.1118 & 0.6546 & 0.0267 & 0.9462 \\
\hline Frequency & time & 0.9491 & 0.2464 & 0.0047 & 0.0073 & 0.8301 & 0.1182 & 0.0007 & 0.0006 & 0.9155 & 0.8789 & 0.3415 & 0.6334 & 0.1528 & 0.0404 & 0.3004 & 0.7478 \\
\hline
\end{tabular}

${ }^{2}$ Values in columns followed by the same letter are not significantly different at $P \leq 0.05$. Values are least square means of at least four replications.

Table 2. Podophyllotoxin, $\alpha$-peltatin, $\beta$-peltatin, and total lignan contents and podophyllotoxin yield of American mayapple leaves. Leaf removal frequency (every year or every 2nd or 3rd year) and timing (early or late season) was investigated using a well-established wild population in shade from 2001 to 2004.

\begin{tabular}{|c|c|c|c|c|c|c|c|c|c|c|c|c|c|c|c|c|c|c|c|c|c|}
\hline \multirow{2}{*}{$\begin{array}{l}\text { Frequency } \\
\text { of harvest }\end{array}$} & \multirow{2}{*}{$\begin{array}{l}\text { Time of } \\
\text { harvest }\end{array}$} & \multicolumn{4}{|c|}{$\begin{array}{l}\text { Podophyllotoxin content } \\
\left(\mathrm{mg} \cdot \mathrm{g}^{-1}\right)\end{array}$} & \multicolumn{4}{|c|}{$\begin{array}{l}\alpha \text {-Peltatin content } \\
\left(\mathrm{mg} \cdot \mathrm{g}^{-1}\right)\end{array}$} & \multicolumn{4}{|c|}{$\begin{array}{l}\beta \text {-peltatin content } \\
\left(\mathrm{mg} \cdot \mathrm{g}^{-1}\right)\end{array}$} & \multicolumn{4}{|c|}{$\begin{array}{l}\text { Total lignan content } \\
\left(\mathrm{mg} \cdot \mathrm{g}^{-1}\right)\end{array}$} & \multicolumn{4}{|c|}{$\begin{array}{l}\text { Podophyllotoxin yield } \\
\qquad\left(\mathrm{mg} \cdot \mathrm{m}^{-2}\right)\end{array}$} \\
\hline & & 2001 & $2002^{z}$ & 2003 & 2004 & 2001 & 2002 & 2003 & 2004 & 2001 & 2002 & 2003 & 2004 & 2001 & 2002 & 2003 & 2004 & 2001 & 2002 & 2003 & 2004 \\
\hline Every year & & 0.000 & 0.018 & 0.042 & 0.233 & 9.3 & 19.3 & $20.1 \mathrm{a}$ & 13.8 & 0.81 & 3.77 & 1.72 & 1.13 & 10.1 & 23.1 & $21.9 \mathrm{a}$ & 15.2 & 0.00 & 0.13 & 0.13 & 1.39 \\
\hline Every 2 years & & 0.000 & --- & 0.031 & --- & 9.6 & --- & $16.1 \mathrm{ab}$ & --- & 0.72 & --- & 1.25 & --- & 10.3 & --- & $17.3 \mathrm{ab}$ & --- & 0.00 & --- & 0.26 & --- \\
\hline Every 3 years & & 0.007 & --- & --- & 0.075 & 10.2 & --- & --- & 11.6 & 0.82 & --- & --- & 0.53 & 11.1 & -- & -- & 12.2 & 0.05 & --- & -- & 0.88 \\
\hline Control 1 & & --- & 0.049 & --- & --- & --- & 17.7 & --- & --- & --- & 3.19 & --- & -- & --- & 21.0 & --- & --- & --- & 0.42 & --- & ---- \\
\hline Control 2 & & --- & --- & 0.016 & --- & --- & --- & $14.0 \mathrm{~b}$ & -- & --- & -- & 0.83 & -- & --- & --- & $14.8 \mathrm{~b}$ & --- & -- & --- & 0.23 & --- \\
\hline \multirow[t]{3}{*}{ Control 3} & & --- & --- & --- & 0.103 & --- & --- & --- & 12.3 & --- & --- & --- & 0.39 & --- & --- & --- & 12.8 & -- & --- & --- & 1.12 \\
\hline & Early & 0.005 & 0.030 & $0.055 \mathrm{a}$ & 0.103 & $11.0 \mathrm{a}$ & $24.0 \mathrm{a}$ & $18.2 \mathrm{a}$ & $13.6 \mathrm{a}$ & $1.32 \mathrm{a}$ & $6.48 \mathrm{a}$ & $2.00 \mathrm{a}$ & $1.16 \mathrm{a}$ & $12.3 \mathrm{a}$ & $30.5 \mathrm{a}$ & $15.8 \mathrm{a}$ & $14.8 \mathrm{a}$ & 0.03 & 0.21 & 0.36 & $0.08 b$ \\
\hline & Late & 0.000 & 0.037 & $0.004 b$ & 0.261 & $8.4 b$ & $13.1 b$ & $15.2 b$ & $11.5 \mathrm{~b}$ & $0.25 b$ & $0.47 b$ & $0.54 b$ & $0.21 \mathrm{~b}$ & $8.7 b$ & $13.6 \mathrm{~b}$ & $10.7 \mathrm{~b}$ & $12.0 \mathrm{~b}$ & 0.00 & 0.34 & 0.05 & $2.18 \mathrm{a}$ \\
\hline \multicolumn{22}{|l|}{ Significance } \\
\hline Frequency & & 0.305 & 0.183 & 0.521 & 0.548 & 0.636 & 0.340 & 0.003 & 0.131 & .867 & 0.431 & 0.078 & 0.064 & 0.578 & 0.316 & 0.004 & 0.052 & 0.371 & 0.168 & 0.808 & 0.885 \\
\hline Time & & 0.380 & 0.731 & 0.014 & 0.062 & 0.008 & $<.001$ & 0.030 & 0.027 & $<.001$ & $<.001$ & $<.001$ & 0.002 & $<.001$ & $<.001$ & 0.008 & 0.011 & 0.290 & 0.511 & 0.077 & 0.024 \\
\hline Frequency & ime & 0.380 & 0.437 & 0.437 & 0.562 & 0.053 & 0.895 & 0.435 & 0.553 & 0.649 & 0.618 & 0.180 & 0.066 & 0.026 & 0.936 & 0.410 & 0.333 & 0.371 & 0.621 & 0.945 & 0.816 \\
\hline
\end{tabular}

${ }^{2}$ Values in columns followed by the same letter are not significantly different at $P \leq 0.05$. Values are least square means of at least four replications. 


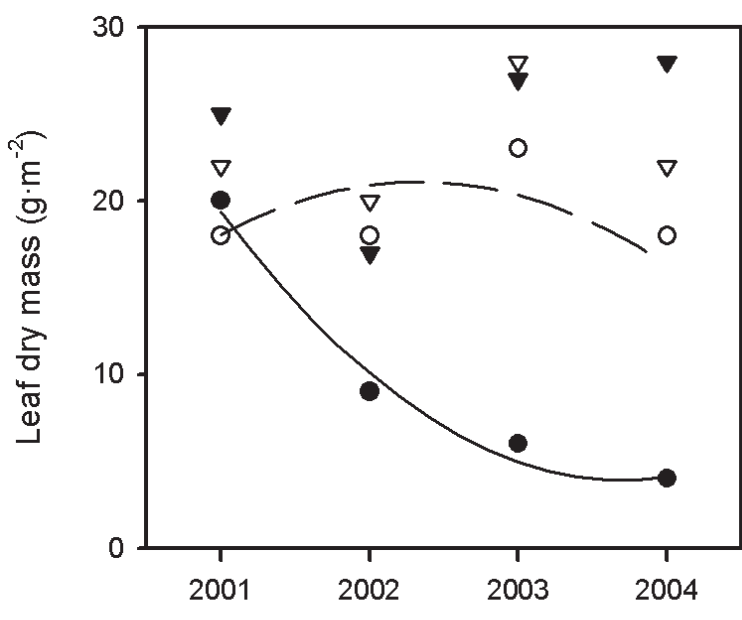

Year
Fig. 1. Leaf dry mass of American mayapple subjected to mild to severe leafremoval treatments. Leafbiomass harvested every year early (solid circle, solid line) or late (open circle, dashed line). Linear and quadratic regression equations were significant. Quadratic equations were $\mathrm{dm}=32.87$ $-15.60 \times$ year $+2.10 \times$ year $^{2}(P \leq$ $0.05)$ for early and $\mathrm{dm}=11.74+8.02$ $\times$ year $-1.72 \times$ year $^{2}(P \leq 0.05)$ for late. Linear and quadratic regressions for controls harvested early (solid triangle) or late (open triangle) were not significant $(P>0.05)$.

accounted for the interaction during 2004: 1) early and 2) late harvest every year. Regardless of year, plants harvested early every year were most affected,
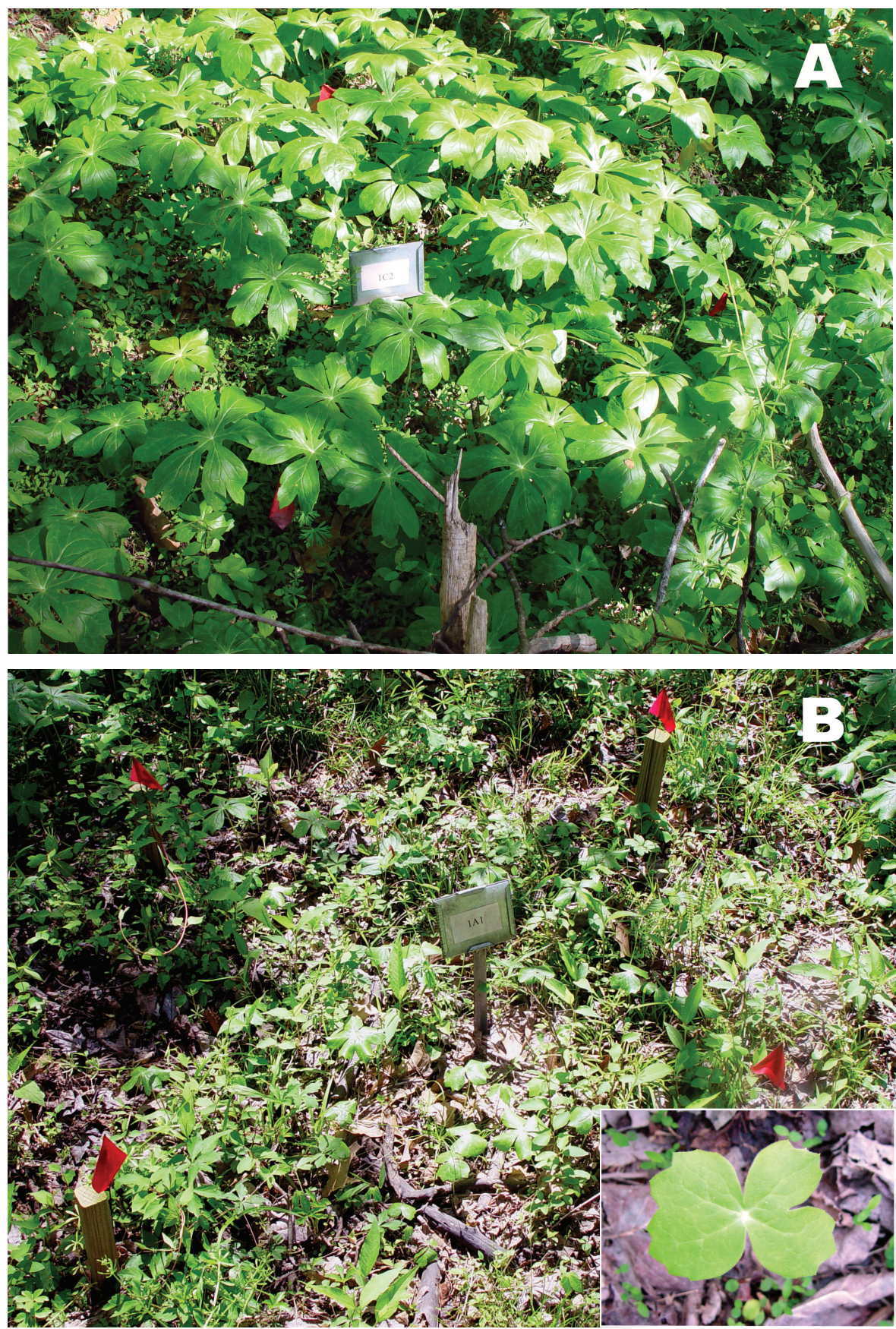

producing significantly less total leaf area and dry mass than any of the other treatment combinations or the controls (Table 1). Plants harvested early every other year or late every year were also affected, producing more total leaf area and dry mass then plants harvested early every year but equal to or less than any of the other treatment combinations. Number of shoots was not affected by treatments at any time during the study (Table 1).

Harvest frequency and harvest time affected number of sexual shoots each year of the study except 2001. There was a significant interaction between main effects during 2002, with plants harvested early every year producing fewer sexual shoots than any of the other treatment combinations (Table 1). Each main effect was significant during 2003, with plants harvested every year producing fewer sexual shoots than plants harvested every other year or control plants and plants harvested early producing fewer sexual shoots than plants harvested late. Only harvest frequency affected sexual shoots during 2004, with plants harvested every year producing fewer sexual shoots than plants harvested every other year or control plants not previously harvested.

Contents of $\alpha$-peltatin, $\beta$-peltatin, and total lignans were higher for leaves harvested early than those harvested late during each year of the study (Table 2). Podophyllotoxin content and podophyllotoxin yield were greater only for leaves harvested early during 2003 and 2004 , respectively.

\section{Discussion}

Results of this leaf removal study using a naturally occurring population of mayapple in shade were similar to those reported for a wild population in full sun (Cushman et al., 2006), except leaf removal treatments affected plants in shade more severely than plants in sun. Leaf area and leaf dry weight of plants harvested early every year in this study were quickly and significantly reduced after one year and continued to decline in subsequent years in a quadratic relationship (Fig. 1). In comparison, leaf area and leaf dry weight of plants in full sun harvested early every year were not as abruptly reduced and, instead, declined steadily in a linear manner throughout the 4 years of the study. Plants in shade did not tolerate the severest of harvest treatments as well as plants in sun. Only one treatment combination negatively impacted long-term growth and performance of plants in sun: annual harvest frequency in combination

Fig. 2. View of two plots before harvest at end of study, Spring 2004. Least severe harvest strategy with plots harvested late in 2001 and not harvested again in later years (A). Shoots were similar in size and growth throughout the study. Most severe harvest strategy with plots harvested early each year from 2001 to 2004 (B). Shoots in B appeared similar to those of $\mathbf{A}$ in 2001 but gradually declined in vigor from year to year. Shoots eventually reverted to juvenile form (inset). Stakes and flags marked 1.0 $\times 1.0-\mathrm{m}$ plots established during Spring 2001 in a wild population growing in mottled shade and located near Natchez, Miss. Other low-growing herbaceous species were common at this site. 
with early harvest time. Our results with plants in shade, however, show three treatment combinations negatively affected long-term growth and performance. From most to least severe they were 1) early harvest every year, 2) late harvest every year, and 3) early harvest every other year. Lubbers and Lechowicz (1989) reported partial leafremoval in T. grandiflorum reduced rhizome density and total nonstructural carbohydrates at the end of the growing season. Our results with the most severe of leaf removal treatments were more dramatic: rhizomes were so weakened they produced shoots with small, juvenile leaves by the end of the 4-year study (Fig. 2).

There was an almost immediate effect of early leaf removal on reproductive fitness, with plants harvested more frequently and earlier producing fewer sexual shoots than any of the other treatment combinations. For plants in full sun, the ratio of sexual shoots to total shoots was reduced to zero only by early annual harvests, though differences were not statistically significant. These results demonstrate again that plants in shade were less tolerant of leaf removal than plants in sun. These results are also consistent with that of Rockwood and Lobstein (1994) where partial defoliation of $J$. diphylla and $T$. sessile tended to reduce reproductive fitness.

Mayapple plants did not produce new leaves in the year in which they were defoliated. As a result, plants did not recover from leaf removal until the following year after defoliation. It was expected that plants subjected to leaf removal early in the season, soon after full leaf expansion, would be affected to a greater extent than plants subjected to leaf removal late in the season. It is also expected that plants subjected to leaf removal every year would be affected to a greater extent than plants subjected to leaf removal every other year or every third year. Our results clearly show that early and frequent leaf removal weakened plants and reduced longterm performance compared to plants grown with foliage intact.

It was recommended for plants in full sun that harvests should be conducted late every year or early or late every 2nd or 3rd year (Cushman et al., 2006). This harvest schedule cannot be recommended for plants in shade because plants in shade did not have the vigor of those in sun. Our results suggest harvests should be conducted late every 2 nd or 3rd year or early every 3 rd year.

Contents of $\alpha$-peltatin, $\beta$-peltatin, and total lignans were higher for leaves harvested early than those harvested late for the duration of the study. Podophyllotoxin content was higher in leaves harvested early only during 2003 . These results were not as striking as for plants in full sun, where podophyllotoxin content was 2.7 to 6.5 times greater in leaves harvested early compared to those harvested late. Differences in lignan contents between leaves harvested early or late appear to be due to differences in physiological age of leaves and not due to treatment. These differences existed during the first year, before leaf removal treatments were applied, and persisted rather consistently throughout the duration of the study. Differences between the two studies are consistent with reports describing a shift in lignan content from relatively higher podophyllotoxin content and lowerpeltatin content in full sun to lower podophyllotoxin content and higher peltatin content in shade (Cushman et al., 2005b; Moraes et al. 2005).

In summary, we can recommend establishing mayapple plantings in full sun and not in shade. Plantings in full sun produce far greater leaf biomass and lignan yield and are more tolerant of leaf removal than plants in shade. If plants in shade must be harvested, we recommend leaf removal every other year if harvests are conducted late in the growing season. Leaf removal late in the season allows plants to accumulate sufficientresources for the next season and does not reduce long-term performance of the mayapple population.

\section{Literature Cited}

Bedows, E. and G.M. Hatfield. 1982. An investigation of the antiviral activity of Podophyllum peltatum. J. Natl. Prod. 45:725-729.

Canel, C., F. E. Dayan, R. M. Moraes, and C. Burandt. 2000 . Enhanced yield of podophyllotoxin from natural products through in situ conversion methods. US Patent 6,143,304. 7 Nov. 2000.

Cushman, K.E. and M. Maqbool. 2005. Propagule type and planting time affect subsequent mayapple growth. HortScience 40:640-644.

Cushman, K.E., M. Maqbool, and P.D. Gerard. 2005a.
Mulch type, mulch depth, and rhizome planting depth for field-grown american mayapple. HortScience 40:635-639.

Cushman, K.E., M. Maqbool, H. Lata, E. Bedir, I.A. Khan, and R.M. Moraes. 2005b. Podophyllotoxin content and yield of american mayapple leaves in sun and shade. HortScience 40:60-63.

Cushman, K.E., R.M. Moraes, E. Bedir, B. Silva, I.A. and Khan. Frequency and timing of leaf removal affect growth and podophyllotoxin content of Podophyllum peltatum in full sun. Planta Med. (in press).

Foster, S. 1993. Medicinal plant conservation and genetic resources: Examples from the temperate northern hemisphere. Acta Hort. 330:67-73.

Jackson, D.E. and P.M. Dewick. 1985. Tumor-inhibitory aryltetralin lignans from Podophyllum pleianthum. Phytochemistry 24:2407-2409.

Lerndal, T. and B. Svensson. 2000. A clinical study of CPH 82 vs. methotrexate in early rheumatoid arthritis. Rheumatology (Oxford). 39:316.

Lubbers, A.E. and M.J. Lechowicz. 1989. Effects of leaf removal on reproduction vs. belowground storage in Trillium grandiflorum. Ecology 70:85-96.

Meijer, W. 1974. Podophyllum peltatum-Mayapple a potential new cash-crop plant of eastern North America. Econ. Bot. 28:68-72.

Moraes, R.M., C. Burandt, Jr., M. Ganzera, X. Li, I. Khan, and C. Canel. 2000. The American mayapple revisited-Podophyllum peltatum - Still a potential cash crop? Econ. Bot. 54:471-476.

Moraes R.M., E. Bedir, H. Barret, C. Burandt, C. Canel, and I. Khan. 2002. Evaluation of Podophyllum peltatum $\mathrm{L}$ accessions for podophyllotoxin production. Planta Med 68:341-344.

Moraes, R.M., H.G. Momm, B. Silva, V. Maddox, G.L. Easson, H. Lata, and D. Ferreira. 2005. Geographic information system method for assessing chemo-diversity in medicinal plants. Planta Med. 71:1157-1164.

Pearce, D.K. and J.W. Thieret. 1993. Persimmon (Diospyros virginiana, Ebenaceae) and Mayapple (Podophyllum peltatum, Berberidaceae): Proximate analysis of their fruit. Trans. Ky. Acad. Sci. Louisville 54(1-2):30-31.

Rai, L.K., P. Prasad, and E. Sharma. 2000. Conservation threats to some important medicinal plants of the Sikkim Himalaya. Biolo. Conserv. 93:27-33.

Rockwood, L.Land M.B. Lobstein. 1994. The effects of experimental defoliation on reproduction in four species of herbaceous perennials from northern Virginia. Castanea 59:41-50. 